East African Medical Journal Vol. 80 No. 9 September 2003

ANOMALIES OF THE RENAL, PHRENIC AND SUPRARENAL ARTERIES: CASE REPORT

M.A.Bakheit, MBBS, PhD, Associate Professor and M.A. Motabagani BSc, PhD, College of Medicine, K.F.U., P.O. Box 2114, Dammam 31451, Saudi Arabia

Request for reprints to: Dr. M. A. Bakheit, Department of Anatomy, College of Medicine, K.F.U., P.O. Box 2114, Dammam, 31451, Saudi Arabia

\title{
ANOMALIES OF THE RENAL, PHRENIC AND SUPRARENAL ARTERIES: CASE REPORT
}

\author{
M.A. BAKHEIT and M.A. MOTABAGANI
}

\begin{abstract}
This is a case where multiple anomalies of the posterior abdominal wall arteries were found. These were accessory renal, a pre-hilar division of the renal, a unilateral origin of the inferior phrenic artery from the renal and aberrant suprarenal arteries. The accessory renal and the pre-hilar branch of the renal resembled polar arteries that supplied the upper and lower poles and similar segments of both kidneys.
\end{abstract}

\section{INTRODUCTION}

Variations in the number of the renal arteries and their position with respect to the renal veins are common; and so are the variations of the suprarenal arteries (1). Accessory renal arteries are commonly derived from the renal, abdominal aorta, common iliac and superior mesenteric arteries. Rarely they originate from the external iliac, lumber, spermatic, ovarian, inferior mesenteric, superior suprarenal, inferior phrenic, right colic, subcostal, contralateral renal, splenic and the thoracic aorta (2-4).

Usually a single inferior phrenic artery arises from the abdominal aorta on each side of the body. They might originate by a common trunk from the aorta, the celiac trunk or independently from the same sources. The inferior phrenic may arise from the renal, left gastric, superior mesenteric, suprarenal; or rarely from the hepatic artery (5-9).

The suprarenal glands are supplied by multiple branches from the inferior phrenic, aorta and renal arteries from above downwards (10). Rare origins from the ureteral and gondal arteries have been described (11).

\section{MATERIALS AND METHODS}

The findings belong to a single male German cadaver during routine dissection in the dissection room(Anatomy Department, College of Medicine, K.F.U., Dammam). The subject was about 50 years old and had an average body weight and height. He seemed to have no injuries and there were no wounds, ulcers and or scratches on the surface of the skin. His face, eyes, nose and mouth were normal and there were no other congenital abnormalities apart from those mentioned above. The cause of death could be due to pulmonary edema or pneumonia as the right lung looked dark black and showed multiple infracts and clots.
RESULTS

On the right side: The renal artery trifurcated into three branches: an upper inferior phrenic artery, a middle prehilar branch and a lower renal artery proper (Figure 1). The inferior phrenic artery passed upwards on the right psoas muscle to the under surface of the right dome of diaphragm. During its course it gave multiple aberrant inferior suprarenal arteries.

The pre-hilar branch divided into upper and lower branches in front of the hilum of the right kidney. The upper branch entered the upper pole of the kidney while the lower branch passed downwards in front of the renal artery to the lower pole of the kidney. It terminated into two branches that entered the lower pole of the kidney. The renal artery itself divided into three terminal branches at the hilum of the kidney.

Figure 1

Posterior abdominal wall on the right side
$A=$ Aorta. $R=$ Renal artery. I=Inferior phrenic artery. $P=$ Pre-hilar branch of the renal $S=$ Suprarenal artery 
Figure 2

Posterior abdominal wall on the left side

A=Aorta. $C=$ Celiac trunk. I=Inferior phrenic artery. $A C=$ Accessory renal artery. $R=$ Renal artery. $S=$ Suprarenal artery

On the left side: The left inferior phrenic artery originated from the aorta above the origin of the celiac truck and passed upwards to the left dome of diaphragm (Figure 2).

A large accessory renal artery originated from the aorta above the origin of the left renal artery; passed downwards in front of the left renal artery to the lower pole of the left kidney. It gave a large aberrant suprarenal branch to the gland and terminated into three branches that entered the lower pole of the kidney. The left renal artery divided into three branches at the hilum. The upper branch gave the inferior suprarenal branch to the left gland

\section{DISCUSSION}

In this case both phrenic arteries, irrespective of their variable origin, ramified into similar branches under the domes of the diaphragm on each side. They did not penetrate the diaphragm or anastomose with any artery fact that excludes their origin from the nearby vessels like the adrenal artery.

The pre-hilar branch of the right renal artery supplied both upper and lower poles of the right kidney, while the accessory renal artery on the left side supplied only the lower pole of the left kidney. Both arteries seemed to have supplied the lower segments in each kidney as well. It is known that the renal arteries divide to give apical, superior (anterior), middle (anterior), inferior (anterior) and posterior branches to supply segments of the same name of each kidney. It therefore seems that the normal segmental blood supply of both kidneys is disturbed by these ectopic vessels. This needs further radiological investigations to clarify the intrarenal distribution of these polar vessels as well as the renal arteries.

The accessory renal artery and the pre-hilar branch, despite of their variable origin, resembled polar arteries that supplied the upper and lower poles of both kidneys. Both vessels or their branches crossed in front of the renal arteries and the ureters to reach the lower pole of each kidney. Such an abnormal course might press on the renal arteries causing ischaemia or on the ureters leading to obstruction and calculi formation.

The polar arteries, accessory renal and the pre-hilar branch are due to persistence of embryonic vessels (12). The abnormal inferior phrenic in this case is due to developmental changes of the right supracardinal artery.

This is a case where multiple anomalies of the posterior abdominal wall arteries were found namely: an accessory renal, a pre-hilar division of the renal, a unilateral origin of the inferior phrenic from the renal and aberrant suprarenal arteries. The accessory renal and the pre -hilar branch resembled polar arteries that supplied the poles and the lower segments of the kidneys. The intrarenal distribution of the renal arteries and these polar vessels require further radiological investigations.

In conclusion vessels having variable origin supplied similar segments of both kidneys. Anomalous vessels crossing in front of the hilar of the kidneys may press on the underneath structures and cause severe pathological conditions.

\section{REFERENCES}

1. Jeffery, R. Unusual origin of renal arteries. Radiol., 1972; 102:309.

2. Skeys, D. The arterial supply of the human kidney with special reference to accessory renal arteries. Brit. J. Surg., 1963; 50:668.

3. Kruyl, R. H. Vascularization of the left kidney by a single vessel originating from the splenic artery. Urology, 1992; 39:487-489.

4. Van Boalin, J. M. and Van Bockel, H. J. Thoracic origin of the right renal artery. J. Vasc. Surg. 1994; 19:762-763.

5. Lin, P. H. and Chalk, E. L. Embryology, anatomy and surgical exposure of the abdominal blood vessels. Surg, Clin. N. Am., 2000; 80:417-433.

6. Anson, B. J. and McVay, C. B. The topographical positions and the mutual relations of the visceral branches of the abdominal aorta. A study of 100 consecutive cadavers. Anat. Rec., 1936; 67:7-15.

7. Nebesar, R. A., Kornbilth, O. L., Pollard, J. J. and Mihels, N. A. Celiac and superior mesenteric arteries: a correlation of angiograms and dissections. Little Brown Co., Boston, 1969; pp. 1-178.

8. Pick, J. W. and Anson, B. J. Inferior phrenic artery: Origin and suprarenal branches. Anat. Rec., 1940; 78:413-427.

9. Grieg, H. W., Anson, B. J. and Colemans, S. S. The inferior phrenic artery. Types of origin in 850 body-halves and diaphragmatic relationship. Quarterly Bull. Northwestern Univ. Med. Sch. 1951; 25:345-350.

10. April, EW. Clinical Anatomy, 3rd edn., Baltimore, Maryland. Williams' \& Wilkins, 1997; 387-388.

11. Merklin, R. J. and Michels, N. A. The variant renal and suprarenal blood supply with data on the inferior phrenic, ureteral and gonadal arteries- A statistical analysis based on 185 dissections and review of the literature. J. Inter. College Surg. 1952; 29:41-76.

12. Moore, K. L. The Developing Human. 3rd. edn., Philadelphia, London. W.B.Saunders Co., 1982; pp. 264-65. 


\section{INFORMATION FOR CONTRIBUTORS}

The East African Medical Journal (EAMJ) aims to improve the practice of all aspects of medicine and health care in general. To achieve these objectives, the journal publishes original scientific articles, reviews, clinical case reports and letters dealing with any factor impacting on health. EAMJ in published monthly since 1923 and is quoted in many authoritative databases including Index Medicus (med-line), SCISEARCH, EMBASE, Current contents clin. med., Sci Cit. Index. Communications should be addressed to the Editor-in-Chief, P.O. Box 41632, 00100, GPO Nairobi, Kenya, Telephone: +254-020-2712010: Facsimile +254-0202724617; E-mail: eamj@wananchi.com.

The EAMJ peer review process: All the manuscripts submitted to the EAMJ are peer reviewed. About one fifth of such manuscripts are rejected after an in-house review by two editors. Primary reasons for rejection at this stage are lack of originality, lack of significant scientific message important to a general medical readership. Such a decision is normally reached within one month.

The remaining manuscripts are sent to one or more external referees selected from a database of many experts. Once returned, those with statistical component are reviewed by a statistician, after which all those considered suitable for publication are discussed at the monthly editorial panel meeting. This is the last stage of the peer review process.

We aim at reaching a final decision on publication within four months of manuscript submission. Original scientific articles and authoritative reviews should be published within four months of being finally accepted or after any necessary revisions.

General instructions: All materials submitted to be considered for publication must be submitted exclusively to EAMJ. It is a condition that all authors must give signed consent to publication. For original Scientific articles and Clinical case reports, written permission must be obtained from the Director/Superintendent of the hospital where the work was done or the case was managed. All manuscripts should be typed in double line spacing on numbered pages and conform to the uniform requirements for manuscripts submitted to biomedical journals(1). Authors should provide their names, addresses and appointment/designation at the time they undertook the study. They should also provide a current address (including telephone, facsimile and E-mail) for purposes of correspondence. From January 2004 a nonrefundable fee of US\$ 50.00 will be levied on all submitted articles. No article will be processed without this fee. Material accepted for publication will be edited including the title. Where possible, proofs are sent to authors of the manuscripts except in the case of letters and obituaries.

Original articles and reviews: Please send three copies. You are advised to keep a further copy for your own reference. Articles should be between two and four thousand words with a maximum of eight tables or other illustrations. Original articles should report data from original research which is relevant to the practice of medicine especially in Kenya, the African continent and developing countries. The message carried in the article should be clear and having the potential of improving the practice of medicine upon implementation. Reviews must be critical analyses of the subjects reviewed, giving a state-of-the art and a balanced view of all the issues, for instance, controversies. Reviews should preferably be contributed by authorities and experts in the respective field. Similar to the case for original articles, the message of the review must be clear and of significance.

A structured abstract of no more than 250 words must be included. For original articles, the abstract should have the following headings: objective(s), design, setting, subjects or participants, interventions, main outcome measures, results and conclusion(2). For reviews the headings should be objectives(s), data sources, study selection, data extraction, data synthesis and conclusions.

Copies of related papers already published should be submitted. This requirement is important where details of study methods are published elsewhere or when the manuscript is part of a series, say, part II of a series where part I has been published elsewhere. Copies of any non-standard questionnaires should also be submitted for consideration of publication as indexes, if deemed necessary.

Statistical methods should be defined and the level of significance used stated.

Editorials: These are usually commissioned, however, unsolicited communications of up to 800 words are welcome. They will be peer reviewed.

Other submissions: (i) Case reports are welcome, however, the reason for presenting them must be clearly stated, particularly their critical significance in clinical practice. Case reports must be authentic, adequately and appropriately illustrated and the identity of any individual concealed according to ethical requirements. They must not be more than one thousand five hundred words which includes a succinct, informative prose summary of no more than one hundred words.

(ii) Letters to the Editor are welcome but must not be more than eight hundred words; contain only one illustration (table or figure) with less than five references. Priority will be accorded to letters responding to articles published in the journal within four months. Letters to the Editor will be edited and may be drastically shortened without losing the gist of the message, but proofs will not be sent to authors.

(iii) Short obituary announcement will be published as soon as possible but in accordance with the policy of the journal. We shall, in addition, be pleased to receive formal obituaries of up to four hundred words accompanied with a good quality pass port size photograph. Formal obituaries should contain, the following information among others: full names, date and place of birth, brief education history, year and place of qualification, all degrees and qualifications, highlights of appointments and achievements, hobbies, etc, mention of family (wife and children, if any), and date and cause of death. Only obituaries of interest to EAMJ readership may be submitted.

Authorship: Although the issue of authorship is currently under discussion, the EAMJ uses the criteria of the uniform requirements for manuscripts submitted to medical journals which state that "authorship credit should be based only on substantial contribution to: (a) conception and design, or analysis and interpretation of data, (b) drafting the article or revising it critically for important intellectual content; and on (c) final approval of the version to be published. Conditions (a), (b) and (c) must all be met. Participation solely in the acquisition of funding or the collection of data does not justify authorship". The EAMJ must be assured that all the authors included on an article do fulfil these criteria of authorship. We also must be assured that there is no one else who fulfils these criteria but has not been included as an author. All the 
authors, except in a posthumous situation, must sign the authors page.

Conflict of interest: Authors of original articles, reviews and letters to the editor should intimate a conflict of interest capable of influencing their judgments. Such conflicts may take many forms; the common ones are financial, personal, political or academic. Authors should disclose the potential conflicts even if they are satisfied that their judgments have not been influenced. The EAMJ deems it reasonable that the readers should know of such conflicts of interest so as to make up their own minds. In particular, sources of funding must be explicitly stated. Reviewers are also required to disclose any conflict of interest.

Ethical issues: Authors are responsible for the views, opinions and authenticity of the material published in the EAMJ. Where applicable, requirements of both international guidelines on research ethics as well as those of the local research ethics committee must be fulfilled, and authors are required to state that this is indeed the case. Attention must be drawn to consent, confidentiality and data ownership. If there is a possibility that a patient may be identified in an article, case report or illustration, the EAMJ advises that the written consent be obtained from the patient or guardian(s).

It is our policy not to print redundant or significantly overlapping publications. For various and valid reasons, the EAMJ does not wish to publish materials that has appeared beforehand in public media. We therefore draw the attention of authors to Ingelfinger rule(3).

Copyright: All authors (with very few specified exceptions) transfer copyright to the EAMJ in accordance with international copyright regulations and also in unison with copyright Act, Chapter 130, Laws of Kenya. Submission of a manuscript, therefore, implies: that the work described has not been previously published (except in the form of an abstract or as part of a thesis); that it is not under consideration for publication elsewhere; that its publication has been approved by all the authors and, in many cases, by the responsible authorities at the institution where the work has been carried out; that if and when the manuscript is accepted for publication, the authors agree to automatic transfer of the copyright to the journal, that the manuscript will not be published elsewhere in any language without consent of the copyright holder.

Format and style: Original articles should conform to the AIMRADAR format, that is, Abstract, Introduction, Materials and methods, Results, and Discussion, Acknowledgments (if any) and References.

Abbreviations, such as, etc., i.e., e.g. should not be used. Internationally recognised abbreviations may only be used after the long form has been written and explained. For instance, the World Health Organisation (WHO), United Nations (UN). Drugs should be referred to by approved and proprietary names. Scientific measurements should be given in SI units, except for blood pressure which should be presented in $\mathrm{mm} \mathrm{Hg}$. Three copies of each manuscripts should be submitted. The entire manuscript must be typed, double spaced throughout, on one side of the paper and with a wide margin. Contributors are also requested to send three copies of Tables and Figures. If the illustrations are photographs (such as, photomicrographs or electron micrographs),three complete sets of glossy prints should be sent. They should not be inserted in the text but should be numbered on the back with figure numbers, caption, title of the paper and name of the author(s). The photographs should be marked 'TOP' where necessary. Photographs, graphs and diagrams will be referred to as figures and should be numbered in Arabic numerals. The position of the illustrations in the text should be clearly indicated. The tables should be essential, numbered consecutively in the text in Arabic numerals and typed on separate pages. Manuscripts should be consistent in style and spelling. Slang, medial jargon and obscure abbreviations must not be used. A title page should be provided to contain: (i) the title of the paper, (ii) author(s) name(s) and signature(s), degrees, designation, name of institution where the work was carried out, present address, telephone and facsimile or telex numbers and e-mail address, if available, and (iii) name and address of the author to whom all communications should be addressed.

\section{REFERENCES}

Only references which are clearly related to the authors work should be quoted. The EAMJ allows up to twenty references for original articles and editorials; up to forty for reviews and only ten or less for case reports. References should be numbered consecutively in the order in which they appear in the text. At the end of the article, the full list of references should give the names and initials of all authors (except where there are more than six when only the first six should be given followed by et al). References made to a journal should include, title of the paper quoted, name of the journal, abbreviated according to the style used in Index Medicus, (see "list of journals indexed", printed yearly in the January issue of Index Medicus); and arranged in Vancouver style, that is, year, volume, first and last page numbers. References made to books should bear the author's or editor's last name, initials, title, edition number, place of publication, publisher and year.

Information from manuscripts not yet in press, papers reported at meetings and conferences, or personal communications may be cited only in the text, not as a formal reference; and even for this an author should get permission from the source to cite personal communication. Authors must check the accuracy and completeness of the references before submitting the article. Only references actually read may be cited and consequently submitted in the list.

Page proofs, offprints and reprints: Page proofs will be submitted, whenever possible, to contributors for minor corrections and must be returned within ten days, as at this time, production is at advanced stages. Neither late nor major changes can be implemented.

Fifty offprints to each article are provided at a charge of US\$71 or Stg£45 plus airmail cost of US\$14 or Stg£9, payable in advance. Authors are advised to submit a cheque together with their order for both offprints and any additional reprints when returning the proofs. Rates are subject to change without notice.

1. Internal Committee of Medical Journal Editors. Uniform requirements for manuscripts submitted to biomedical journals, PA: ICMJE, 1963.

2. Haynes, R.B., Mulrow, C.D., Huth, E.J., Attman, D.G. and Gardner, M.J. More informative abstracts revisited. Ann. Intern. Med. 1990; 113:69-76.

3. Editorial. The Ingelfinger Rule revisited. New. Engl. J. Med. 1991; 235:1371-1373. 